\title{
UNA APROXIMACIÓN A LAS RELACIONES ENTRE EL TURISMO MOCHILERO Y LA CULTURA CORPORATIVA GLOBAL
}

\author{
Antonio MARTÍN-CABELLO; Almudena GARCÍA-MANSO \\ Universidad Rey Juan Carlos (España) \\ antonio.martin@urjc.es, almudena.manso@urjc.es
}

\section{AN APPROACH TO THE RELATIONSHIPS BETWEEN BACKPACKER TOURISM AND GLOBAL CORPORATIVE CULTURE}

Resumen: Este artículo trata de explorar las relaciones que existen entre una de las subculturas juveniles globales más extendidas: los mochileros, y la cultura de las grandes corporaciones globales encarnada en el colectivo de los trabajadores expatriados. Para ello, en primer lugar, se revisarán los estudios sobre los mochileros para describir su perfil sociodemográfico más habitual y las características de su cultura. Posteriormente, se recogerán los estudios que analizan las competencias que adquieren los mochileros durante sus viajes. En tercer lugar, se describirán las características de la cultura de los expatriados corporativos. Finalmente, se discutirá la relación entre el viaje mochilero, la adquisición de competencias y la inclusión en el mundo de los expatriados corporativos. Se pretende, en definitiva, construir un discurso crítico en el cual las subculturas de los mochileros y de los expatriados corporativos son vistas como variaciones de una cultura capitalista transnacional.

Abstract: This paper tries to explore the relationship between one of the most widespread global youth subcultures: backpackers, and the culture of global corporations represented by expatriate workers. To do this, first, the article reviews studies on backpackers in order to describe its most common social and demographic profile and the characteristics of their culture. Subsequently, it collected the studies which examining the skills acquired by backpackers while traveling. Third, the characteristics of the culture of corporate expatriates will be described. Finally, the paper discusses the relationship between backpacking, the acquisition of skills and the backpacker inclusion in the world of corporate expatriates. In short, the main goal is to build a critical discourse in which backpacker and corporate expatriate subcultures are seen as variations of a transnational capitalist culture.

Palabras clave: Cultura corporativa; Expatriados, Globalización; Mochileros; Turismo Corporative Culture; Expatriates; Globalization; Backpackers; Tourismo 


\section{Introducción}

"Soy hijo del camino, caravana es mi patria y mi vida la más inesperada travesía" (Amin Maalouf).

La globalización es un proceso que supone un reto a la sociología, no solo por la superación del llamado "nacionalismo metodológico", sino porque implica un desafío a los métodos sociológicos habituales. La movilidad e indefinición de los colectivos globales hacen que los procedimientos de investigación estándar sean de difícil, aunque no de imposible, aplicación. Las investigaciones sobre las subculturas globales suelen pivotar en torno a estudios cualitativos con pequeñas muestras sin un afán longitudinal. En este artículo se pretende realizar una primera aproximación a las conexiones entre dos colectivos que han creado sutiles culturas globales: los turistas mochileros (backpackers) y los expatriados corporativos. Para ello, se revisará y se utilizará la literatura académica disponible. Curiosamente, los mochileros han recibido una mayor atención desde la literatura de carácter sociológico y antropológico que los expatriados corporativos. Estos últimos han sido ampliamente analizados desde el mundo del management, pero han recibido menor atención etnográfica. Además de la revisión de la literatura académica se han analizado libros y revistas, de un lado, y páginas web, foros y comunidades, de otro, dirigidas tanto a los mochileros como a los expatriados.

En un artículo anterior se presentó una investigación en la que se trataba de compara los estudios sobre mochileros en otras partes del mundo con la experiencia mochilera en Chile (Martín-Cabello, 2014). En el mismo se advirtieron fuertes continuidades entre la subcultura mochilera internacional y la subcultura que estaba presente entre los mochileros en ese país. Se pudo comprobar que el grueso de los mochileros eran estudiantes egresados que tomaban un tiempo tras sus estudios para viajar. Una cuestión que surgió de este hecho fue el carácter de este viaje, ya que en el discurso de los mochileros esa experiencia parecía tener algún tipo de vinculación con su posterior inclusión en la esfera del trabajo. Así, se pretende analizar los vínculos entre el turismo mochilero y la cultura de las corporaciones transnacionales, a priori la más afín a la experiencia mochilera. Para ello, se analizarán las competencias adquiridas en el viaje y su relación con las requeridas por las corporaciones a sus trabajadores globales.

El artículo en primer lugar analizará el perfil de los jóvenes que practican el turismo mochilero y los rasgos de la subcultura que comparten. Seguidamente, describirá las habilidades clave (Key Skills) que según la escasa literatura académica disponible adquieren o mejoran durante el viaje mochilero. En tercer lugar, se planteará la existencia de una elite corporativa global que comparte rasgos culturales congruentes con las habilidades adquiridas en el viaje mochilero y con algunos rasgos de su subcultura. En la discusión y las conclusiones se tratará de analizar críticamente la relación de este tipo de turismo joven con el modelo capitalista global que se desarrolla actualmente y que representan los expatriados corporativos.

\section{Nómadas globales: mochileros}

"No se consideraba un turista; él era un viajero. Explicaba que la diferencia residía, en parte, en el tiempo. Mientras el turista se apresura por lo general a regresar a su casa al cabo de algunos meses o semanas, el viajero, que no pertenece más a un lugar que al siguiente, se desplaza con lentitud durante años de un punto a otro de la tierra" (Paul Bowles).

Millares de jóvenes deciden cada año iniciar una experiencia en torno al turismo que les 
sumerge en una subcultura particular. El concepto de mochilero hace referencia a un tipo de turista que realiza un viaje auto-gestionado de larga duración con múltiples destinos a los que se llega a través de un itinerario flexible. Suele asociarse también a un desembolso económico reducido y a un uso mínimo de la industria turística habitual. En general, este tipo de turista rechaza clasificarse como tal y afirma buscar un contacto más profundo con la naturaleza o con la población de los países que visita (Maoz, 2007: 123). En las publicaciones acerca del fenómeno, se han creado toda una serie de denominaciones para referirse a ellos: "viajeros", "vagabundos" (Cohen, 1973), "trotamundos" (Vogt, 1979), "viajeros de larga duración" (Ateljevic y Doorne, 2000) o, entre otras, "nómadas globales" (Richards y Wilson, 2004). La más habitual dentro de la literatura científica, sin embargo, es la de "mochileros". Estos acostumbran a darse a sí mismos el nombre de "viajeros" o "mochileros" para diferenciarse de los turistas (O’Reilly, 2005: 155-156).

Respecto a las características más habituales de los mochileros internacionales, aunque no son un grupo homogéneo, se han citado las siguientes. En primer lugar, proceden de los países desarrollados, sobre todo de occidente: Norteamérica, Australia y Nueva Zelanda, Europa, Israel y Japón. Suelen ser más hombre que mujeres, un $60 \%$ de hombres frente a un $40 \%$ de mujeres. Su edad está comprendida entre los 18 y los 33 años, encontrándose el grupo más numeroso entre los 22 y los 27. La mayor parte tiene estudios universitarios. Suelen viajar solos o con un único acompañante durante un periodo comprendido entre los 2 y los 18 meses, siendo un año la duración más habitual (Sørensen, 2003).

Cualquier cultura puede fragmentarse analíticamente en tres grandes conjuntos: su estructura de significados, las prácticas a las que da lugar y los artefactos asociados a la misma. La estructura de significados está compuesta por un entramado valorativo y normativo, que genera un conjunto de roles y unos mitos e ideologías que la explicitan. Las prácticas reflejan los rituales y los estilos de vida construidos y reconstruidos a través de las interacciones. Finalmente, los artefactos serían los objetos en que se proyecta y objetiva esa cultura (Carrithers, 1992; Jenks, 1993; Kuper, 1999). La subcultura mochilera, en consecuencia, genera una estructura de significados propia, una serie de prácticas compartidas y unos artefactos comunes, que surgen de las interacciones de sus miembros y de las redes que estos crean más allá de sus países de origen.

La subcultura mochilera descansa en la diferenciación entre dos roles: el mochilero, definido mayoritariamente como un viajero, frente al turista. De hecho, el rol del mochilero se construye en contraposición al del turista (Cohen, 2010). Esta distinción se puede rastrear bastante atrás. En la novela de Paul Bowles The Sheltering Sky (2000), publicada originalmente en 1949, ya se encontraba presente, como también recoge su adaptación al cine por Bernardo Bertolucci en 1990. La distinción entre los turistas y los viajeros, sin ser explícitamente formulada como en el caso de Bowles, se encuentra por toda la novela de Jack Kerouac On the Road (1959) publicada originalmente en 1957. Se halla plagada de referencias negativas hacia el turista, que realiza un viaje distinto al de los protagonistas. Narra, por ejemplo, la reacción de los lugareños de un pueblo mexicano ante su presencia: "La visión de tres jóvenes americanos sucios y barbudos en lugar de los turistas habituales bien vestidos fue inusualmente interesante para ellos". En estos viajeros sucios y barbudos debía estar pensando Erik Cohen (1973) cuando los describía como "vagabundos". Un planteamiento similar aparece en la novela de Paul Theroux The Happy Isles of Oceania de 1992: "Pienso que los turistas no saben dónde han estado. Los viajeros no saben dónde van a ir" (en Wilson y Richards, 2004: 134).

Estos relatos literarios y cinematográficos tienen su reflejo en las guías de viaje que utilizan los mochileros y que explicitan la ideología del viaje propia de esta subcultura. En la famosa guía de Lonely Travel South-East Asia on a Shoestring, conocida entre los mochileros como "la Biblia Amarilla" (Riley, 1988: 323), se remarca claramente esta diferenciación de roles: 
"Si tengo que definir mi creencia sobre el viaje, esta es que si has estado en algún lugar y has permanecido en el Hotel Hilton local, probablemente no has estado allí (...). Los turistas se quedan en los Hoteles Hilton, los viajeros no. Ellos quieren ver el país a pie de calle para respirarlo, experimentarlo y vivirlo. Eso habitualmente requiere dos cosas que el turista no puede conseguir: más tiempo y menos dinero" (en Sørensen, 2003: 862).

Esta pauta se refleja en los relatos de los propios mochileros. Hamzah Muzaini recoge las palabras de Jon, un mochilero británico, en las que expresa esta idea:

"No, no soy un turista. No quiero ser unido con el turista que viaja en un paquete turístico y va a un país por unos pocos días, apuntando muchas atracciones turísticas en su lista de cosas a visitar en el país, haciéndose fotografías en ellas y comprando toneladas de souvenires como prueba de que han estado allí. No soy como todos ellos. No hago esas cosas. Soy un viajero local" (2006: 152).

Los mochileros, por tanto, prefieren verse como viajeros que "persiguen la autenticidad y experimentar aspectos no corrompidos de la sociedad anfitriona" (Ooi, 2002: 69). Maccannell (1976) mantenía que esa búsqueda en el destino turístico era resultado de la percepción del origen como un lugar contaminado e inauténtico. El turista buscaría la autenticidad fuera de casa, aunque luego no encontrara sino una representación de la misma. La subcultura mochilera incidiría en la consecución de lo genuino, que se encontraría más allá de la representación. Lo auténtico se hallaría al margen del turismo estandarizado, en el "mundo real". El mochilero, por tanto, huiría de las construcciones turísticas que no muestran la realidad del país visitado, sino una construcción elaborada para el turista del destino elegido. Pese a los problemas teóricos que pueda suponer la idea de autenticidad (Olsen, 2002), lo cierto es que los propios mochileros suelen citar ese valor como uno de los principales motivos que los llevan a emprender un viaje de ese tipo (Noy, 2004: 85).

Otros valores propios de la subcultura son el ansia de libertad y la frugalidad. La autoexpresión y la capacidad de dirigir uno mismo su propia vida es un elemento central en esta subcultura. Los mochileros consideran que esta es una forma de viajar más "libre" y menos limitada (Wilson y Richards, 2008: 22). El rechazo de la riqueza y del materialismo, aunque sea durante un corto periodo de la vida, es otro valor clave dentro de la subcultura mochilera. "La pobreza es representada como una simplificación positiva, una vuelta atrás a los aspectos básicos de la vida" (Binder, 2004: 104).

Estos roles y valores, generan una serie de creencias ampliamente compartidas entre los mochileros. En primer lugar, se encuentra la creencia de que "lo auténtico está fuera del hogar". Esta creencia descansa en una clara separación entre la sociedad de origen (nosotros) y la sociedad receptora (ellos). El viaje se plantea como una salida del inauténtico occidente contaminado por la modernidad, hacia un tercer mundo (o un primer mundo alternativo) alejado de la corrupción que impera en el lugar de origen. Esta forma de ver al otro guarda estrechos vínculos con la noción de orientalismo (Said, 1977), como una forma de distorsión romántica del oriente por parte de los viajeros occidentales. Los mochileros comparten una visión orientalista del país visitado como un entorno más simple, puro, inocente y auténtico (O’Reilly, 2006: 1003).

En segundo lugar, los mochileros piensan que en el viaje se "viven relaciones auténticas" o, al menos, más auténticas que las habituales. Una de las motivaciones clave citada por los mochileros es la de conocer gente en el camino (Riley, 1988), que conforman "la gran familia" de los viajeros (Binder, 2004). Y, en tercer lugar, creen que a través del viaje se puede "conocer de verdad el territorio y la gente a la que se visita". Chaim Noy afirma, en este sentido, que en las narrativas que realizan los propios mochileros sobre sus viajes 
aparecen frecuentemente "las personas maravillosas y extraordinarias que conocieron y los lugares que vieron" (2004: 86).

Dentro de la subcultura existe, finalmente, un arquetipo que sirve de modelo conductual: el aventurero. Este descubre su propio camino, nunca prefijado de antemano, lo cual implica viajar fuera de los circuitos comerciales. La novela de Alex Garland The Beach (2007), de indudable éxito comercial, y la película homónima dirigida por Danny Boyle y protagonizada por Leonardo DiCaprio, exploran la imagen del mochilero como un aventurero que vive experiencias al margen de los circuitos turísticos. Algunas investigaciones afirman que escritores y viajeros que escriben su experiencia como Ernest Hemingway, Jack Kerouac, Hunter S. Thompson, Bruce Chatwin, Paul Theroux, Michael Palin o Bill Bryson son verdaderos iconos de la subcultura mochilera, pues explicitan una imagen romántica del aventurero y del viaje como descubrimiento y justifican la separación entre el turista y el viajero (Wilson y Richards, 2004).

El conjunto de valores (autenticidad, libertad, frugalidad), roles (mochilero/turista), creencias (lo auténtico está fuera del hogar, el mochilero vive relaciones auténticas, el mochilero conoce de verdad el país de acogida y su gente) y arquetipos (la imagen del aventurero) configuran un discurso bien definido y un verdadero sustrato significativo sub-cultural, que genera una "visión compartida del mundo" (O’Reilly, 2006: 999) entre los jóvenes viajeros.

Este marco de referencia sub-cultural es el que tienen en cuenta los mochileros cuando tratan de conseguir un "estatus como viajero" (road status), que demuestre su grado de integración en la subcultura mochilera. La búsqueda de un estatus es básica en la práctica del turismo mochilero, ya que estructura las interacciones que estos mantiene durante el viaje real. Para conseguir un alto estatus como viajero, este ha de mostrar señales como el uso de ropa desgastada, la capacidad de alojarse y mantenerse gastando poco dinero y la habilidad de narrar sus experiencias enfatizando los elementos desagradables y peligrosos del viaje así como las diferencias entre su modo de actuar y el de los otros: locales y turistas (Sørensen, 2003). En todo caso, este estatus supone la negociación del marco de referencia con la realidad del viaje. El grado de sinceridad o cinismo con el que se actúa es variable (Goffman, 1959), pero siempre implica una negociación entre la realidad del viaje y las exigencias de la subcultura mochilera compartida. Según algunos autores, los mochileros se parecen más por compartir unas prácticas, que por tener actitudes y motivaciones comunes (Uriely et al., 2002). Es decir, las prácticas en relación a la subcultura describirían mejor a los mochileros que unas supuestas características psicológicas unitarias.

Aunque la subcultura mochilera mantiene que este tipo de viaje permite relacionarse más con la población local, la realidad es que permite relacionarse más con otros mochileros. Es más, "algunos estudios sugieren que los mochileros tienen poco interés en conocer a la población local y aprender acerca de su cultura" (Maoz, 2007:124). Lo que parece cierto es que las interacciones sociales preponderantes se realizan con otros mochileros. Los alojamientos son un factor clave en la consolidación de estas rutas preestablecidas y tienen un papel relevante en la construcción de una subcultura mochilera. Los mochileros pasan la mayor parte de su tiempo en los albergues y hostales o viajando hacia los mismos y solo una minoría pasa la mayor parte de su tiempo con la población local (Cohen, 2004:46-47). Los albergues y hostales, por tanto, son verdaderos "enclaves" en los que medra y se perpetúa la subcultura, y pueden ser vistos como espacios alternativos a los lugares donde se desarrolla la vida diaria (Shields, 1991). Julie Wilson y Greg Richards mantienen, sin embargo, que los enclaves para mochileros son "«un hogar cultural lejos del hogar» donde aparece un orden social temporal, generalmente con el inglés como lengua franca" (2008: 13).

La subcultura mochilera cuenta con toda una serie de artefactos que la recogen, solidifican, explicitan y le sirven de símbolos identitarios. Además, existe una verdadera industria en torno al fenómeno, encargada de proporcionar estos materiales a los mochileros presen- 
tes o futuros. En primer lugar, ha quedado documentado un uso intensivo de las guías de viaje por parte de los mochileros (Adler, 1985; Riley, 1988) y actualmente también de Internet (Sørensen, 2003; Richards y Wilson, 2004). En este sentido, ciertos estudios sugieren que el acceso a Internet en el destino reduce la dependencia de las guías (Newlands, 2004: 228). Para algunos estudios estas guías de viaje funcionan como verdaderos símbolos de la subcultura mochilera (Currie et al., 2011). Las más usadas parecen ser Lonely Travel -con gran diferencia sobre las demás-, Foot Print, Le Guide du Routard y Rough Guide (Oliveira, 2008:99).

Existe una abundante literatura de viajes, tanto de ficción como de viajes reales, en la cual se describe la experiencia mochilera. Posiblemente una de las novelas más influyentes, junto a las citadas anteriormente, haya sido The Drifters (1971) de James Michener. Podrían señalarse otras más recientes, simplemente a modo de ejemplo, Chasing Dreams (2008) de Aaron Jennings, Backpack de Emily Barr (2002), Are you Experienced? (1997) de William Sutcliffe o The Backpacker (2001) de John Christopher Harris. En el ámbito hispano hablante destacan, por su impacto y difusión, los diarios que escribió Ernesto "Che" Guevara para describir el viaje que hizo con un compañero a través de América Latina en 1952 y que publicó bajo el título de Diarios de motocicleta (2005). También existen publicaciones periódicas, como Wanderlust, Backpacker, TNT o British Balls dirigidas a este segmento de viajeros y gran cantidad de sitios web dedicados a este tipo de turistas como www.bootsnAll.com, the-backpacking-site.com, la página web de las guías Lonely Travel o mochileros.org en el mundo de habla hispana. Se han citado algunas películas basadas en libros de referencia para la comunidad mochilera y en Australia incluso se han producido algunas series de televisión como Crash Palace, ambientada en un hostal de mochileros. El papel de la literatura de viajes y de otras expresiones en los medios de comunicación no debe minusvalorarse, pues muchos mochileros leen estas novelas, libros de viajes y revistas o ven esas series de televisión y películas como preparación de su viaje, e incluso durante el mismo.

Otro rasgo destacado de la subcultura mochilera sería su representación en la persona misma de los mochileros. El vestido es un rasgo distintivo. Los mochileros suelen vestir con ropa deportiva llamada "ropa de viaje" y "ropa de exterior". Existe una industria que les proporciona dichas prendas, con un conjunto de marcas bien conocidas como The North Face, Trango World o, solo por citar algunas, Nordica; y de tiendas en la que adquieren esas prendas como Decathlon, Go Outdoors o Nacional Geographic Store. Junto a la ropa, suelen llevarse botas, gorros y, con cierta frecuencia, bastones para caminar, además de las características mochilas. También es habitual el uso de pantalones cortos, lo que en muchos contextos choca con las costumbre locales, y de gafas de sol. Todo ello configura un estilo mochilero reconocible.

\section{Aprendiendo a trabajar (y vivir) en un mundo global a través del viaje}

"Los viajes son en la juventud una parte de educación y, en la vejez, una parte de experiencia" (Francis Bacon).

El título de este apartado hace referencia al trabajo clásico de Paul Willis (1977). En el mismo, se describían las experiencias escolares de los jóvenes británicos procedentes de la clase obrera que favorecían su inclusión exitosa en el mundo del trabajo disponible para los adultos de esa misma clase. En la actualidad, la escuela y las instituciones de educación superior continúan siendo claves en el proceso de adquisición de las competencias necesarias para la integración en cualquiera de los diferentes segmentos que componen el mercado laboral. Las credenciales académicas, como analizó hace ya unos años Randall Collins (1979), ejercen un papel fundamental en ese campo. Sin embargo, han surgido nuevas experiencias socializadoras que también proporcionan competencias altamente valoradas por el mercado. Una de ellas, como se mostrará a continuación, es la del viaje, en especial, 
del viaje mochilero.

La relación entre el aprendizaje y los viajes no es nueva, aunque no ha sido tan ampliamente explorada como otras implicaciones del turismo (Falk, 2012). En el siglo XVII y XVIII era frecuente que los jóvenes pertenecientes a la aristocracia o la alta burguesía británica realizaran un viaje que se denominaba Grand Tour (Brodsky-Porges, 1981). Con el mismo se pretendían que además de realizar un viaje de placer, adquiriesen una serie de habilidades que les serían de importancia en su posterior vida profesional dedicada a tareas diplomáticas o al comercio internacional. En el otro extremo de la escala social, lo jóvenes de la clase obrera británica practicaban el Tramping durante el siglo XIX, un tipo de viaje local en busca de trabajo (Adler, 1985). En ambos casos, la relación entre viaje y educación estaba clara tanto para los individuos que participaban de la experiencia como para sus coetáneos.

En esta línea se ha descrito el viaje de los mochileros como una experiencia eminentemente educativa o que, al menos, tiene importantes consecuencias educativas para sus participes. Así, George Gmelch (1997) planteaba respecto a los estudiantes norteamericanos que viajaban por Europa de un modo autónomo, que lo que aprendían de los lugares y culturas donde vivían era muchas veces superficial. Sin embargo, era una experiencia altamente formativa. El aprendizaje provenía fundamentalmente de la necesidad de tomar decisiones en entornos no familiares. Los estudiantes se volvían más confiados, independientes y adaptables.

Posteriormente, Philip L. Pearce y Faith Foster (2007), en un artículo ampliamente citado en investigaciones posteriores, analizaron las competencias genéricas (Generic Skills) obtenidas en el viaje que una muestra de mochileros australianos enunciaban y consideraban importantes en sus futuros empleos. En la Tabla 1 se muestra las 12 competencias genéricas que consideraron más importantes y como habían mejorado gracias a su viaje en una escala de cuatro puntos. Cuando se pregunto a esos mochileros como mostrarían a un futuro empleador que el viaje es una experiencia útil para su desempeño profesional, respondieron señalado algunas de las competencias genéricas más habituales: adquisición de habilidades sociales, autogestión, sensibilización social y cultural, independencia, afrontar las dificultades, autoconfianza y resolución de problemas (Pearce y Foster, 2007: 1296).

Tabla 1. Importancia de las competencias genéricas para los viajeros y cantidad de mejorar debida al viaje.

\begin{tabular}{|l|l|}
\hline Clasificación por importancia & Cantidad media de mejora \\
\hline 1. Confianza en sí mismo (34\%) & 3,25 \\
\hline 2. Tener la mente abierta (17\%) & 3,12 \\
\hline 3. Gestión de los recursos financieros (16\%) & 3,18 \\
\hline 4. Independencia (15\%) & 3,41 \\
\hline 5. Comunicación efectiva (13\%) & 3,24 \\
\hline 6. Adaptabilidad (12\%) & 3,24 \\
\hline 7. Sentirse a gusto con todo tipo de personas (12\%) & 3,16 \\
\hline 8. Toma de decisiones (12\%) & 3,00 \\
\hline 9. Comprensión y sensibilización (11\%) & 3,28 \\
\hline 10. Tolerancia (9\%) & 3,29 \\
\hline 11. Disposición a asumir riesgos (9\%) & 3,06 \\
\hline 12. Lidiar con presiones, emociones y estrés (8\%) & 3,31 \\
\hline
\end{tabular}

Fuente: Pearce y Foster, 2007: 1293. (El porcentaje de la primera columna indica la cantidad de entrevistados que incluyeron estas competencias entre las tres más importantes). 
El deseo de adquirir nuevas habilidades y experiencias, así como de relacionarse con otras culturas está presente en la mayoría de las descripciones de las motivaciones de los mochileros para emprender el viaje (Young y Lyons, 2010). Janice Scarinci y Philip Pearce (2012) confirmaron recientemente en un estudio las competencias enunciadas por Pearce y Foster, a saber, independencia, apertura mental, sentirse cómodo en lugares extraños con todo tipo de gente y las habilidades comunicativas. Algunas investigaciones han mostrado también que no solo los mochileros piensan que esta experiencia es positiva porque refuerza la independencia de los participantes, sino que los empleadores también lo creen (Nash y Bruce, 2012). Si bien ese mismo estudio mostró que las habilidades consideradas importantes por los mochileros no coincidían con las que enfatizaban los empleadores.

Kerr Inkson y Barbara Myers (2003) sostuvieron analizando el viaje mochilero de jóvenes australianos y neozelandeses que aunque existían multitud de motivaciones para emprender el viaje, para la mayoría el desarrollo profesional era una de ellas. Además, sostenían que los expatriados corporativos solían recomendar ciertas estrategias de carreras internacionales antes de la expatriación, entre las que entraban claramente el turismo mochilero. Si fuese de otro modo no se comprendería que "instituciones educativas, empresas, gobiernos, organizaciones sin ánimo de lucro e intermediarios estén apoyando a los estudiantes para mejorar sus competencias transculturales viajando al extranjero" (van't Klooster et. al., 2008: 691).

\section{Nómadas corporativos: expatriados}

"Formo parte de esa cultura global empresarial. Viajamos en clase Business, leemos el Financial Times y sufrimos jet lag permanente. Y puedo asegurarte que esa gente no tiene la menor idea de hasta qué punto se ha aislado del resto del mundo" (Peter Nolan, en Robinson, 2013: 28).

La existencia de clases sociales globales es motivo de polémica y disputa entre los académico que estudian el fenómeno de la globalización. No obstante, existe al menos una abundante literatura científica que sostiene la existencia de elites transnacionales con intereses comunes. Según Richard Sennett (2011), la emergencia de la burguesía como clase social dominante en el siglo XIX supuso la aparición de una elite cosmopolita que tenía algunas características de una clase social internacional. Esta clase capitalista transnacional se habría desarrollado y en la actualidad, afirma Leslie Sklair (1995, 2001, 2002a, 2002b, 2002c), sería la verdadera elite dirigente. Según esta autora, sus miembros pueden ser localizados en cuatro esferas: los ejecutivos de las corporaciones globales, los políticos y burócratas de las organizaciones transnacionales, los técnicos globales y los profesionales de los medios de comunicación, que crean una cultura de consumo mundial. Todos ellos forman parte de una elite dominante, lo que no significa que sus intereses sean convergentes en todas las ocasiones ni que, en otras, puedan competir entre ellos por diversos motivos. Es más, incluso pueden competir con otros capitalistas anclados localmente, ya que no son una clase occidental, sino parte de un capitalismo global integrado.

William Robinson y Jerry Harris (2000), y posteriormente el primero en solitario (2004), hablaban de la formación de una clase capitalista mundializada autoconsciente que habían creado un aparato de control en forma de organizaciones estatales transnacionales: el Banco Mundial, el Fondo Monetario Internacional o, entre otras, la Organización Mundial del Comercio. Esta clase trataría de integrar a las elites económicas nacionales en un bloque que situaría sus intereses en la esfera transnacional. Para finalizar un recuento que podría ser más amplio, recientemente George Corm (2012) planteaba que es innegable la existencia de la clase global, a la que denomina una "aristocracia del dinero", basada en una economía de la renta. Esta se estructuraría en cuatro niveles descendentes. En el superior se encontrarían 
los millonarios y dueños de las grandes corporaciones transnacionales. Debajo de ellos se situarían los directivos y gestores de esas corporaciones. En un tercer estrato se hallarían los miembros de las grandes burocracias internacionales. Por último, en la base de la clase capitalista mundializada estarían los pequeños ahorradores que prefieren especular en la economía internacional que en actividades propiamente productivas.

En todo caso, los técnicos y directivos de las grandes corporaciones transnacionales y los burócratas y políticos que forman parte de las organizaciones internacionales estarían encuadrados dentro de esa nueva elite. Hace ya más de tres décadas Ulf Hannerz (1990) buscaba definir a los cosmopolitas frente a los locales. Pensaba que el cosmopolita es una persona que puede desvincularse de su localidad y vivir en otras culturas, pues sus intereses vitales dependen de la comunidad transnacional. Es un individuo que puede vivir en otra cultura sin implicarse en ella y que es capaz de saltar a un nuevo enclave cultural cuando lo considera oportuno. Entre este tipo de personas no se encuentran los turistas -más espectadores que participes-, los "hombres de negocios" que viajan de hotel en hotel, los exiliados o en los inmigrantes laborales. Este papel queda reservado para los "expatriados", que "han elegido vivir en el extranjero por algún tiempo, y que saben cuando están allí que pueden volver a casa cuando deseen" (Hannerz, 1990: 243). Estos viven y generan "culturas transnacionales", que son en gran medida transformaciones de la cultura occidental. Estas permiten, por un lado, sentirse a los miembros occidentales de las mismas "en casa" y son una experiencia distintiva para los no occidentales y, por otro lado, son un trampolín para acceder a otras culturas.

Un caso particular y especialmente numeroso es el de los expatriados corporativos, o nómadas corporativos, que pueden definirse como trabajadores de las grandes corporaciones transnacionales o de las burocracias internacionales que voluntariamente, aunque por lo habitual recompensados con importantes mejoras en sus condiciones laborales, se trasladan a países diferentes al de origen durante un periodo de tiempo prolongado. El tiempo de estancia suele pactarse con el empleador, aunque el empleado tiene la posibilidad de volver en un tiempo prudencial cuando lo decida -en el peor de los casos podría rescindir su relación laboral y regresar al hogar-. En general, puede hablarse de los expatriados corporativos como de "inmigrantes privilegiados", por su nivel adquisitivo y tratamiento tanto por la empresa que los desplaza como, con mucha frecuencia, por las autoridades del país receptor.

En 2013 el National Foreing Trade Council realizó una encuesta a 1.511 expatriados en todo el mundo de la que surgió el siguiente perfil. El $80 \%$ eran hombre frente a un $20 \%$ que eran mujeres. El $84 \%$ de los expatriados estaban casados y sus edades se distribuían así: $17 \%$ entre 25 y 34 años, $29 \%$ entre 35 y 44, 29\% entre 45 y 54 y $20 \%$ entre 55 y 64. Un $49 \%$ procedía de Norteamérica, un 22\% de Europa, un 13\% de Asia, un 6\% de América Central y del Sur, un 4\% de Australia y Oceanía y el 6\% restante de África y Oriente Medio. Solamente Estados Unidos concentraba un $42 \%$ de todos los expatriados. Esto no resulta extraño si se tiene en cuenta que las sedes centrales de las compañías para las que trabajaban estos expatriados se localizaban en Estados Unidos en el 82\% de los casos y en Europa en un 10\% de ellos (NFTC, 2013). Sin embargo, otros estudios con muestras aún más amplias señalan que las proporciones de expatriados en función de su nacionalidad varían mucho de un país a otro (HSBC Expat, 2012).

Existe cierta cantidad de literatura académica sobre los expatriados, aunque fragmentaria y centrada mayoritariamente en aspectos de gestión de los trabajadores expatriados, en especial su selección, entrenamiento y los problemas de lo que denominan "ajuste", esto es, su adaptación a la cultura del país al que son destinados (p.e. Mirabal Martínez y Zapata Rotundo, 2009; Pascual Faura, 2006; Sanchez Vidal et al., 2005). Encontramos, por tanto, abundante literatura sobre el modo de gestionar la expatriación, pero pocos recuentos sociológicos o antropológicos sobre los expatriados. En todo caso, es posible plantear desde 
la misma que los expatriados generan y viven una de esas culturas transnacionales de las que hablaba Hannertz.

Richard Sennett $(1998,2006)$ señalaba cuatro rasgos básicos de la personalidad del trabajador buscado por las grandes corporaciones globales: flexibilidad y capacidad de desprenderse del pasado, aceptación del desorden y la fragmentación, flexibilidad mental para resolver problemas y capacidad para trabajar en equipos de corta duración. Estos son congruentes con las habilidades solicitadas a los candidatos a la expatriación en los manuales sobre gestión, a las que habría que sumar lo que se denominan habilidades de comunicación y gestión intercultural (Gaggiotti, 2006; Lin et al., 2012). Según un estudio realizado por IESE y Ernst and Young:

"Los factores más valorados por las empresas, según los encuestados, para seleccionar a los expatriados son los conocimientos técnicos y experiencia $(4,2)$ y la consideración de su carrera profesional $(3,9)$ A continuación, por orden de importancia, se encuentran otros aspectos como la capacidad de adaptación cultural $(3,8)$, la capacidad de liderazgo $(3,7)$ y las habilidades de negociación $(3,5)$. Los dos factores con menor consideración por parte de la empresa para seleccionar a los futuros expatriados, según estos últimos, son la experiencia internacional previa $(3,3)$ y las circunstancias familiares $(2,9)$ " (s.f.: 7$)$.

A partir de esta imagen ideal del expatriado, tal como plantean los departamentos de gestión de recursos humanos, surge una cultura sutil y polimórfica, pero con algunos rasgos comunes. Un primer rasgo distintivo de la misma es la movilidad, con el avión como metáfora y el hotel como enclave (Friedman, 2003). El avión se constituye en la mejor representación de una movilidad mediatizada por el sistema capitalista (Anta, 2013), dentro del cual trabajan los expatriados, y el aeropuerto y los concomitantes hoteles en la del llamado "espacio de flujos" (Castells, 2000). El expatriado vive en un entorno local pero desde una posición móvil. El local tomará el avión para pasar unas vacaciones o visitar a un familiar, en lo que constituye una experiencia significativa única, mientras que el expatriado vive el desplazamiento como rutina y el anclaje en el territorio como un interludio entre viajes.

Cuando los expatriados viven en un entorno local ajeno a su tierra de origen existen estudios de caso que afirman que suelen interactuar con los locales educados al modo occidental en contextos laborales, mientras que mantienen sus relaciones en su hogar temporal con otros expatriados de similares orígenes culturales (Beaverstock, 2002). Algunos de estos estudios muestran que los expatriados suelen tener escasas relaciones con los locales y que suelen desconocer su lengua (Fechter, 2007). Esto último no es extraño, dentro de una comunidad que usa el inglés como lengua franca. En un manual dirigido a futuros expatriados se puede leer acerca de los problemas de comunicación que encontrará un hombre de negocios estadounidense que desee vivir y trabajar en Europa:

"Las diferencias comienzan con el lenguaje. Los 15 países de la Unión Europea comparten 11 lenguas oficiales. A las mismas se añaden cerca de 50 leguas minoritarias, como el catalán y el flamenco. Cincuenta millones de personas en la Unión Europea hablan una de esas lenguas minoritarias como su primera lengua. Y cada una de esas lenguas tiene un bagaje cultural distintivo. Nadie espera que un hombre de negocios estadounidense hable alguna de esas lenguas excepto el inglés, pero esperan que sea sensible a los diferentes modos de pensar y actuar. [...] Los que son hablantes de inglés nativos, incluyendo a los estadounidenses, tienen derecho a sentirse afortunados porque el inglés es el lenguaje de los negocios internacionales." (Adams, 1998: cap. 3, cursiva nuestra). 
Las relaciones de los expatriados se configuran en redes transnacionales que operan a través de entidades enraizadas en lo translocal (Beaverstock, 2005). Dicho de otro modo, los expatriados suelen relacionarse con los locales más próximos culturalmente en el entorno laboral y con otros expatriados en su tiempo libre a través de redes ancladas en lo local pero con proyección internacional que les permiten mantener y acrecentar su red de contactos global. Un ejemplo serían los clubes y locales dirigidos a los expatriados (Beaverstock, 2011). También existen etnografías que muestran las estrategias de los expatriados para recrear el hogar lejos de su tierra, generando enclaves propios (Lauring y Selmer, 2009; Porter, 2009), en lo que se ha llamado una "caja de oro" o "burbuja" (Fechter, 2007).

Este hecho no implica que los expatriados, pese a su posición privilegiada en el país de acogida, gocen de una situación segura. Vered Amit-Talai (1997) mostró que los expatriados en Islas Caimán no tenían una posición consolidada y solían afirmar que su estancia allí les sumía en un "limbo". No tenían asegurado el puesto al regresar a su país de origen y, además, la red de contactos entre los expatriados no era algo que pudiese darse por supuesto. Esto implica que los expatriados viven en una cultura en la que deben soportar un algo grado de incertidumbre, ya que las relaciones laborales y sociales no están aseguradas.

En todo caso, las experiencias de los expatriados occidentales no son las únicas, ya que expatriados de otras nacionalidades muestran estrategias adaptativas diferentes -un ejemplo puede ser el de los expatriados japoneses en Estados Unidos (Yamazaki y Christopher, 2007)-. Aunque, bien es cierto, la mayor parte de las corporaciones occidentales aún continúan teniendo un origen occidental ${ }^{1}$ y el equipo gerencial es reclutado mayoritariamente entre los miembros partícipes de su cultura matriz - lo cual no significa que sean miembros de la nación origen de la corporación, pero sí que han sido educados en la cultura gerencial global compartida por las mismas-. Algunos autores afirman que los expatriados construyen una zona de seguridad en la que la alteridad es definida de un modo limitado, olvidando la historia y la geografía del entorno que habitan. Esto permite que realicen negocios independientemente de su localización, operando desde una lógica neoliberal (Hindman, 2009).

Respecto a la cultura material asociada a los expatriados corporativos existen abundantes publicaciones en forma de manuales y libros de ayuda y apoyo al expatriado (Adams, 1998; Hachey, 2010; Kohls, 2001; Kontrimas, 2006; Reuvid, 2009), y cuentan con revistas como Global Living Magazine, Expatriate Living for the International LifeStyle en Londres, Expatriates Magazine en París, Expatriate Lifestyle o The Expat en Malasia o centradas en un colectivo específico de expatriados como The Expatriate, focalizada en los expatriados africanos. También existen comunidades web de expatriados, como www.expatriates.com, www.expat-blog.com, www.expatnetwork.com o www.internations.org. Además, habría que sumar la literatura económica y de negocios internacionales que se encuentra ligada es esta subcultura.

\section{Discusión: de mochileros, competencias genéricas y expatriados corporativos}

"Una (...) tendencia importante de la distinción cultural de las élites en la sociedad informacional es crear un estilo de vida e idear formas espaciales encaminadas a unificar su entorno simbólico en todo el mundo, con lo que suplantan la especificidad histórica de cada localidad" (Manuel Castells).

Hasta el momento se han analizado tres fenómenos que, en principio, no tienen mucho

\footnotetext{
1 Antoni Verger afirmaba que en el año 2000 había en el mundo aproximadamente 60.000 empresas transnacionales, que controlaban aproximadamente las dos terceras partes del comercio mundial y el $85 \%$ de la inversión directa en el extranjero. Además, "de las 60.000 empresas multinacionales que existen, unas 50.000 tienen matriz en un país desarrollado. En cambio, de 820.000 filiales solo 100.000 se encontraban ubicadas en los países desarrollados" (Verger, 2003: 82).
} 
que ver entre sí: el turismo mochilero, la adquisición de competencias genéricas a través del viaje y la existencia de una subcultura propia de los expatriados corporativos. Más arriba hacíamos referencia al trabajo de Paul Willis (1977) en el que se estudiaba la incorporación de los jóvenes de clase obrera al mundo del trabajo. Según Willis, la estructura de la subcultura juvenil en la escuela británica basada en un modelo nosotros-ellos que enfrentaba a alumnos, de clase obrera, y profesores, de clase media, a través de una serie de acciones encaminadas a "gestionar" el conflicto y resistir la cultura del otro, era congruente con la cultura de los talleres (workshop culture) en la que estaban destinados a trabajar dichos jóvenes. Estos, cuando abandonaban la escuela y se incorporaban al taller encontraban continuidades más que notables. Los chicos de clase obrera se "sentían como en el hogar".

En este artículo se mantiene que la subcultura mochilera también presenta continuidades con la cultura laboral corporativa de las compañías multinacionales representada por los expatriados. Los jóvenes mochileros sienten, como les ocurría a los jóvenes obreros estudiados por Willis, que "están en casa" tras incorporarse a la multinacional. Con esto, no se afirma que todos los viajeros que optan por realizar un viaje de larga duración, equipados con una mochila y no demasiado dinero, terminen trabajando en una compañía multinacional. Esto no ocurre ni siquiera entre los jóvenes universitarios, pues muchos de ellos terminan realizando otros tipos de trabajos. Simplemente se señala que existe una continuidad entre ambas experiencias, que produce que aquellos que llegan a ocupar un puesto en las compañías multinacionales encentren una conexión entre ambas sub-culturas y se integren más rápidamente en las mismas.

En consecuencia, no hay un vínculo directo entre la experiencia mochilera y la experiencia de los expatriados corporativos. Sin embargo, si se detecta cierto grado de "homología estructural" (Hebdige, 2001) entre las sub-culturas que generan ambos colectivos. La creación de redes transnacionales, la vida en enclaves dentro de contextos culturales locales, el uso del inglés como lengua franca, las relaciones restringidas dentro del colectivo y con los locales enculturados en esas sub-culturas, o la creación de una imagen multi-culturalista e integradora en lo valorativo son rasgos compartidos por ambos colectivos. Es decir, inclusión en lo simbólico y exclusión en las prácticas cotidianas. A ello habría que sumar la creación de un estilo diferencial en la cultura material.

Los estudios parciales que existen sobre la adquisición de competencias a través del viaje, en general como complemento a la formación universitaria, muestran que tanto los mochileros como los empleadores consideran que la experiencia del viaje mochilero es congruente con un futuro desempeño profesional como expatriado. Dicho de otro modo, se considera que las habilidades adquiridas durante el viaje mochilero son las habilidades que serán necesarias para el trabajo dentro de las grandes corporaciones transnacionales.

En esto existe una contradicción entre el discurso imperante de la inter-culturalidad, que se mantiene dentro de ambas sub-culturas, y la realidad de la integración de los mochileros y expatriados en los contextos locales, que suele ser escasa. Así, muchos expatriados terminan residiendo en enclaves "más familiares", donde comparten espacio vivencial con otros expatriados y donde es posible "cultivar" las relaciones necesarias para mantenerse dentro de esa elite transnacional. Del mismo modo, los mochileros terminan transitando por rutas para mochileros y residiendo en albergues y hostales que solamente ocupan ellos.

Se han realizado analogías con la experiencia colonial, en la que los "amos" de la metrópoli construían enclaves en los países ocupados desde los que poder controlar el territorio, al tiempo que se creaba una retórica humanitaria e internacionalista con objeto de dominar a la población local (Said, 1977). En este sentido, en términos experienciales el expatriado corporativo no se encuentra lejos del delegado comercial de la East India Company o la Compagnie des Indes Orientales, aunque el poder descarnado sea ahora manejado en términos de poder simbólico (Lee, 2013; Leggett, 2010). Lo mismo ocurre con el turismo mochilero, del que se han de hecho importantes analogías neocoloniales (Teo y Leong, 2006). 
Por último, resulta significativo que contemos con un mayor volumen de estudios sobre el turismo mochilero que sobre las elites corporativas globales ${ }^{2}$. Este hecho puede deberse a dos factores. En primer lugar, la mayor dificultad de estudiar los grupos de elite, que son más refractarios al enfoque etnográfico. Y, en segundo lugar, una menor presencia pública del objeto de estudio. Los mochileros son una subcultura visualmente impactante que se concentran en enclaves concretos. Los expatriados corporativos se reúnen en enclaves más difusos, aunque no inexistentes, y no presentan una cultura material tan distintiva -en muchos sentidos las élites globales tienden a copiar el estilo de las élites transnacionales y, en ocasiones, resultan indistinguibles-. En todo caso, aparece como un área de enorme interés el estudio monográfico de esta subcultura global.

\section{Conclusiones}

En este artículo se ha tratado de mostrar los vínculos que existen entre la subcultura que genera el turismo mochilero y la que surge de la existencia de trabajadores expatriados por las grandes corporaciones globales. No se ha pretendo establecer relaciones de causalidad, que requerirían una investigación ulterior, sino simplemente mostrar los vínculos estructurales que existen entre dichas culturas. Se ha intentado plantear que ambas son expresiones de una emergente, y cada vez más consolidada, cultura capitalista global o cultura-mundo, que si bien no hace desaparecer las diferencias locales, si crea un sustrato significativo común compartido por grupos de personas en todo el planeta.

No es lugar para realizar una valoración de la existencia de estos colectivos y de sus subculturas, tarea más propia de la filosofía política, pero sí de señalar su emergencia y la fuerza con la que están operando. No es posible entender nuestro mundo sin aceptar este hecho. Y, en este sentido, convendría realizar un mayor esfuerzo etnográfico en torno a los expatriados -los mochileros han sido estudiados con mayor profusión-, cuya cultura apenas ha sido descrita pese a su importancia. Lo global se desarrolla en las relaciones de las mujeres y los hombres que viven esa cultura.

\section{Bibliografía}

ADAMS, John W.

1998 U.S. Expatriate Handbook. Guide to Living and Working Abroad. Virginia: West Virginia ADLER, Judith University College. http://www.us-expatriate-handbook.com/contents.htm (02-06-2014).

1985 "Youth on the road: reflections on the history of tramping", en Annals of Tourism Research, 12 (3): 335-354.

AMIT-TALAI, Vered

1997 "In precarious motion: From territoriality to transnational cultures", en The Canadian Journal of Sociology and Anthropology, 34 (3): 319-332.

ANTA FÉLEZ, José Luis

2013 "Una etnografía del avión: cuerpos sujetos a la disciplina del consumo viajero", en AIBR. Revista de Antropología Iberoamericana, 8 (3): 323-344.

ATELJEVIC, Irena y DOORNE, Stephen

2000 "Tourism as an escape: long-tern travellers in New Zealand", en Tourism Analysis, 5: 131136.

BARR, Emily

2002 Backpack. London: Plume.

2 Ahora bien, algunos estudios recientes vienen a suplir esta carencia. Destaca, por ejemplo, el estudio sobre los interlocking directorates, es decir, sobre las redes de directivos o consejeros que pertenecen a varias empresas multinacionales simultáneamente, que ha publicado Julián Cárdenas (2014). 
BEAVERSTOCK, Jonathan V.

2002 "Transnational elites in global cities: British expatriates in Singapore's financial district", en Geoforum, 33: 525-538.

2005 "Transnational elites in the city: British highly-skilled inter-company transferees in New York City's financial district", en Journal of Ethnic and Migration Studies, 31 (2): 245268.

2011 "Servicing British expatriate «talent» in Singapore: Exploring ordinary transnationalism and the role of the «expatriate» club", en Journal of Ethnic and Migration Studies, 37 (5): 709-728.

BINDER, Jana

2004 "The whole point of backpacking: Anthropological perspectives on the characteristics of backpacking", en Richards, G. y Wilson, J. (Eds.), The Global Nomad. Backpacker Travel in Theory and Practice: 92-108. Clevedon: Channel View Publications.

BOWLES, Paul

2000 The Sheltering Sky. London: Harper Collins. (Orig. 1949).

BRODSKY-PORGES, Edward

1981 "The grand tour travel as an educational device 1600-1800", en Annals of Tourism Research, 8 (2): 171-186.

CÁRDENAS, Julián

2014 El poder económico mundial. Análisis de redes de interlocking directorates y variedades de capitalism. Madrid: CIS.

CARRITHERS, Michael

1992 Why Humans Have Cultures? Explaining Anthropology and Social Diversity. Oxford: Oxford University Press.

CASTELLS, Manuel

2000 La era de la información. Economía, sociedad y cultural. Vol 1. La sociedad red. Madrid: Alianza.

COHEN, Erik

1973 "Nomads from affluence: Notes on the phenomenon of drifter tourism", en International COHEN, Scott Journal of Comparative Sociology, 10: 373-392.

2004 "Backpacking: Diversity and change", en Richards, G. y Wilson, J. (Eds.), The Global Nomad. Backpacker Travel in Theory and Practice: 43-59. Clevedon: Channel View Publications.

2010 "Reconceptualising lifestyle travellers: Contemporary «drifters»", en Hannam, K. y Diekmann, A. (Eds.), Beyond Backpacker Tourism. Mobilities and Experiences: 64-84. Bristol: Channel View Publications.

COLLINS, Randall

1979 The Credential Society. An Historical Sociology of Education and Stratification. New York: Academic Press.

CORM, Georges

2012 El nuevo gobierno del mundo. Ideologías, estructuras, contrapoderes. Barcelona: Península.

CURRIE, Russell R. et al.

2011 "Joining the in-crowd: Symbols for backpacker identity", en International Journal of Culture, Tourism and Hospitality Research, 5 (1): 47-56.

FALK, John H.

2012 "Travel and learning: a neglected tourism research area", en Annals of Tourism Research, 39 (2): 908-927.

FECHTER, Anne-Meike

2007 Transnational Lives: Expatriates in Indonesia. Aldershot, UK: Ashgate.

FRIEDMAN, Jonathan

2003 "Los liberales del champagne y las nuevas clases peligrosas: reconfiguraciones de clase, identidad y producción cultural”, en García, J. L. y Barañano, A. (Coords.), Cultura en contacto. Encuentros y desencuentros: 161-197. Madrid: Ministerio de Educación, Cultura y Deporte. 
GAGGIOTTI, Hugo

2006 "Un ignorado espacio social: un marco teórico para el análisis de la denominada «expatriación》 de directivos multinacionales”, en Scripta Nova, X (226).

GARLAND, Alex

2007 The Beach. London: Penguin.

GMELCH, George

1997 "Crossing cultures: Student travel and personal development", en International Journal of Intercultural Relations, 21 (4): 475-490.

GOFFMAN, Erving

1959 The Presentation of Self in Everyday Life. New York: Anchor Books.

GUEVARA, Ernesto

2005 Diarios de motocicleta. Notas de un viaje por América Latina. Buenos Aires: Planeta.

HACHEY, Jean-Marc

2010 The Big Guide to Living and Working Overseas. Indiana: Indiana University.

HANNERZ, Ulf

1990 "Cosmopolitans and Locals in World Culture", en Theory, Culture \& Society, 7: 237-251.

HARRIS, John Chirstopher

2001 The Backpacker. Chichester: Summersdale.

HEBDIGE, Dick

$2001 \quad$ Subculture. The Meaning of Style. London: Routledge.

HINDMAN, Heather

2009 "Cosmopolitan codifications: Elites, expatriates, and difference in Kathmandu, Nepal", en

HSBC Expat Identities, 16 (3): 249-270.

2012 Expat Explorer Survey 2012. London: HSBC.

IESE y ERNST and YOUNG

s.f. $\quad$ El proceso de expatriación en empresas multinacionales: visión del expatriado. Madrid: IESE y Ernst and Young.

INKSON, Kerr y MYERS, Barbara A.

2003 "The big OE: Self-directed travel and career development", en Career Development International, 8 (4): 170-181.

JENKS, Chris

1993 Culture. London: Routledge.

JENNINGS, Aaron

2008 Chasing Dreams. London: Legent Press.

KEROUAC, Jack

1959 On the Road. New York: Viking Press.

KOHLS, L. Robert

2001 Survival Kit for Overseas Living: For Americans Planning to Live and Work Abroad. London: Nicholas Brealey Publishing.

KONTRIMAS, Andrius

2006 International Expatriate Employment Handbook. Alphen aan den Rijn, The Neterhlands: Kluwer Law International.

KUPER, Adam

1999 Culture. The Anthropologists'Account. Cambridge, Mass.: Harvard University Press.

LAURING, Jakob y SELMER, Jan

2009 "Expatriate compound living: An ethnographic field study", en International Journal of Human Resource Management, 20 (7): 1451-1467.

LEE, Daphnee Hui Lin

2013 "Bourdieu's symbolic power and postcolonial organization theory in local-expatriate relationships: An ethnographic study of a French multinational corporation in Singapore", en Current Sociology, 61 (3): 341-355.

LEGGETT, W. H.

2010 "Institutionalising the colonial imagination: Chinese middlemen and the transnational corporate office in Jakarta, Indonesia”, en Journal of Ethnic and Migration Studies, 36 (8): 1265-1278. 
LIN, Carol Yeh-Yun, LU, Ting-Chun y LIN, Hsiao-Wen

2012 "A different perspective of expatriate management", en Human Resource Management Review, 22: 189-207.

MAALOUF, Amin

2013 León el Africano. Madrid: Alianza.

MAOZ, Darya

2007 "Backpackers' Motivations. The role of culture and nationality", en Annals of Tourism Research, 34 (1): 122-140.

MARTÍN-CABELLO, Antonio

2014 "El turismo Backpacker en Chile como expresión de una subcultura juvenil global", en Cuadernos de Turismo, 34, julio-diciembre. [En prensa].

MCCANNELL, Dean

1976 The Tourist. A New Theory of the Leisure Class. New York: Schocken.

MICHENER, James

1971 The Drifters. New York: Random House.

MIRABAL MARTÍNEZ, Alberto y ZAPATA ROTUNDO, Gerardo

2009 "Estructura y expatriación: riesgos en la asignación externa para expatriados que aprenden”, en Ciencias económicas, 27 (2): 21-32.

MUZAINI, Hamzah

2006 "Backpacking southeast Asia. Strategies of «Looking Local»", en Annals of Tourism Research, 33 (1): 144-161.

NASH, Robert y BRUCE, Fiona

2012 "Backpacker travel and graduates' future employability", en CAUTHE 2012: The New Golden Age of Tourism and Hospitality. Book 2. Proceedings of the $22^{\text {nd }}$ Annual Conferen$c e$ : 440-446. Melbourne, Vic.: La Trobe University.

NEWLANDS, Ken

2004 "Setting out on the road less travelled: a study of backpackers travel in New Zealand", en Richards, G. y Wilson, J. (Eds.), The Global Nomad. Backpacker Travel in Theory and Practice: 217-236. Clevedon: Channel View Publications.

NFTC

2013 Expatriates Trends Study 2013: Understanding their Perspective. Washington: NFTCCGHB.

NOY, Chaim

2004 "This trip really changed me. Backpackers' Narratives of Self-Change”, en Annals of Tourism Research, 31 (1): 78-102.

OLIVEIRA, Rui José de

2008 "Turismo Backpacker - Estudo dos viajantes internacionais no Brasil”, en Cultura. Revis-

OLSEN, Kjell ta de Cultura e Turismo, 1: 89-104. http://uesc.br/revistas/culturaeturismo. (11-10-12).

2002 "Authenticity as a concept in tourist research. The social organization of the experience of authenticity", en Tourism Studies, 2 (2): 159-183.

OOI, Can-Seng

2002 Cultural Tourism and Tourism Cultures. The Business of Mediating Experiences in Copenhagen and Singapore. Copenhagen: Copenhagen Business School Press.

O’REILLY, Camille

2005 "Tourist or traveller? Narrating backpacker identity", en Jaworsky, A. y Pritchard, A. (Eds.), Discourse, communication and Tourism: 150-169. Clevedon: Channel View Publications.

2006 "From drifter to gap year tourism. Mainstreaming backpacker travel", en Annals of Tourism Research, 33 (4): 998-1017.

PASCUAL FAURA, Marcelo

2006 "La gestión de la expatriación: conceptos y etapas clave", en Boletín económico del ICE, 2870: 43-53.

PEARCE, Philip L. y FOSTER, Faith

2007 “A «university of travel»: Backpacking learning”, en Tourism Management, 28: 12851298. 
PORTER, Lisa

2009 "Transnational spaces: U.S. expatriates recreating home in Costa Rica", en International Journal of Interdisciplinary Social Sciences, 3 (10): 217-223.

REUVID, Johathan

2009 Working Abroad: The Complete Guide to Overseas Employment and Living in a New Country. London: Kogan Page.

RICHARDS, Greg y WILSON, Julie

2004 "The global nomad: Motivations and behaviour of independent travellers worldwide", en Richards, G. y Wilson, J. (Eds.), The Global Nomad. Backpacker Travel in Theory and Practice: 14-39. Clevedon: Channel View Publications.

RILEY, Pamela J.

1988 "Road culture of international long-term budget travellers", en Annals of Tourism Research, 15 (3): 313-328.

ROBINSON, Andy

2013 Un reportero en la montaña mágica. Cómo la élite económica de Davos hundió el mundo. Barcelona: Ariel.

ROBINSON, William I.

2004 A Theory of Global Capitalism. Production, Class and State in a Transnational World. Baltimore: John Hopkins University Press.

ROBINSON, William I. y HARRIS, Jerry

2000 "Towards a global ruling class? Globalization and the transnational capitalist class", en

SAID, Edward Science and Society, 64 (1): 11-54.

1977 Orientalism. London: Penguin.

SANCHEZ VIDAL, María Eugenia, BARBA ARAGÓN, María Isabel y SANZ VALLE, Raquel

2005 "Estudio cualitativo sobre la gestión de la repatriación en las empresas internacionales", en Revista de economía y empresa, 2 (52-53): 67-85.

SCARINCI, Janice y PEARCE, Philip

2012 "The perceived influence of travel experiences on learning generic skills", en Tourism Management, 33 (2): 380-386.

SENNETT, Richard

1998 The Corrosion of Character. The Personal Consequences of Work. New York: WW. Norton.

2006 The Culture of New Capitalism. New Haven: Yale University.

2011 El declive del hombre público. Barcelona: Anagrama. (Orig. 1977).

SHIELDS, Rob

1991 Places on the Margin. Alternative Geographies of Modernity. London: Routledge.

SKLAIR, Leslie

1995 The Sociology of the Global System. Baltimore: John Hopkins University Press.

2001 The Transnational Capitalist Class. Oxford: Blackwell.

2002a "The transnational capitalist class and global politics: deconstructing the Corporate-State connection", en International Political Science Review, 23, 2: 159-174.

2002b "La clase capitalista transnacional y el discurso de la globalización", en Revista Mexicana de Ciencias Políticas y Sociales, XLV, 186: 133-156.

2002c "Democracy and the transnational capitalist class", en Annals AAPSS, 581: 144-157.

SØRENSEN, Anders

2003 "Backpacker Ethnography", en Annals of Tourism Research, 30 (4): 847-867.

SUTCLIFFE, William

1997 Are you Experienced? London: Penguin.

TEO, Peggy y LEONG, Sandra

2006 "A postcolonial analysis of backpacking", en Annals of Tourism Research, 33 (1): 109131.

URIELY, Natan et al.

2002 "Backpacking experiences. A type and form analysis", en Annals of Tourism Research, 29 (2): 520-538. 
VAN'T KLOOSTER, Erik, VAN WIJK, Jeroen, GO, Frank y VAN REKOM, Johan

2008 "Educational travel. The overseas intership", en Annals of Tourism Research, 35 (3): 690711.

VERGER, Antoni

2003 El sutil poder de las transnacionales. Lógica, funcionamiento e impacto de las grandes empresas en el mundo globalizado. Barcelona: Icaria.

VOGT, Jay W.

1976 "Wandering: Youth and travel behaviour", en Annals of Tourism Research, 4 (1): 25-41.

WILLIS, Paul

1977 Learning to Labour. How Working Class Kinds Get Working Class Jobs. Westmead, UK: Saxon House.

WILSON, Julie y RICHARDS, Greg

2004 "Backpackers icons: Influential literary «nomads» in the formation of backpackers identities”, en Richards, G. y Wilson, J. (Eds.), The Global Nomad. Backpacker Travel in Theory and Practice: 123-15. Clevedon: Channel View Publications.

2008 "Suspending reality: An exploration of enclaves and the backpacker experience", en Hannam, K. y Ateljevic, I. (Eds). Backpackers Tourism. Concepts and Profiles: 9-25. Clevendon: Channel View Publications.

YAMAZAKI, Yoshitaka y CHRISTOPHER, Kayes D.

2007 "Expatriate learning: Exploring how Japanese managers adapt in the United States", en International Journal of Human Resources Management, 18 (8): 1373-1395.

YOUNG, Tamara y LYONS, Kevin

2010 "«I travel because I want to learn $\gg:$ Backpackers and the conduits of cultural learning", en Lifelong Learning in Europe, 15 (3): 150-158. 